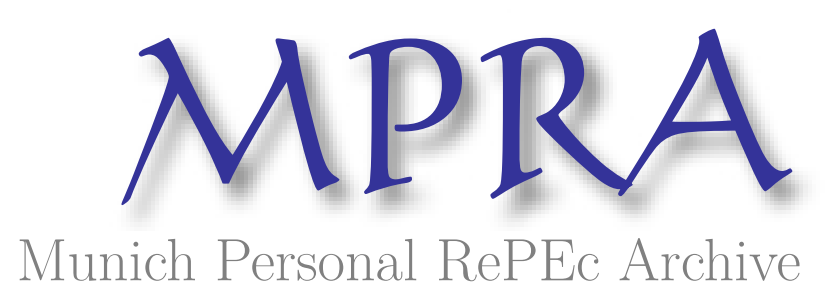

\title{
The effects of inflation on growth: some international evidence
}

Grimes, Arthur

1991

Online at https://mpra.ub.uni-muenchen.de/68526/

MPRA Paper No. 68526, posted 05 Jan 2016 02:02 UTC 


\section{The Effects of Inflation on Growth: Some International Evidence}

Arthur Grimes ${ }^{1}$

\section{Introduction}

Diverse perceptions exist regarding the influence of inflation on economic growth. The theoretical literature (particularly of the new classical school) gives little cause for believing that sustained inflation can permanently affect the real growth rate, in either a positive or a negative direction. This paper tests the validity of this view. It uses evidence from 21 industrial countries over 27 years to ascertain whether inflation has had any systematic influence (positive or negative) on economic growth rates.

Many economists consider that price stability is beneficial to resource allocation, so enhancing either the level or the growth rate of economic activity. The corollary is that inflation is harmful to economic growth. One channel by which this effect may operate is if there is a positive correlation between the inflation rate and the variability of inflation [Logue and Willett, 1976], and if the variability in the rate of inflation impacts negatively on production decisions [Friedman, 1977]. Feldstein [1982] outlines another channel, whereby inflation interacts with a nominal tax system to raise the cost of capital, so discouraging investment and hence growth.

The Keynesian tradition, however, tends to support the opposite conclusion. For instance, the standard Phillips curve posits that higher inflation is correlated with reduced levels of unemployment and higher levels of activity. According to this view, changes to the rate of inflation should impact positively on growth. There are a number of micro-foundations for this result, including the existence of adaptive inflation expectations, or the use of overlapping contracts in the labour market [Fischer, 1977]. The Tobin-Mundell hypothesis that an increase in inflation will cause greater investment in fixed capital, also leads to an expected positive impact of the change in inflation on economic growth.

In order to examine which of these views are consistent with the empirical evidence, the paper examines whether there are any systematic empirical impacts of the inflation rate and the change in the inflation rate on economic growth across countries over time. The relationship between inflation and the level of economic activity is not analysed, on the grounds that if inflation is found to impact on the growth rate, this effect is likely to be more important than any one-off impact on the level of output. The welfare costs of inflation are also not specifically addressed in the study, having already been extensively examined by Fischer [1981b]. The paper confines its attention to empirical matters, so as to uncover the international "stylised facts" on the relationship between inflation and growth.

Intertemporal cross-country comparisons have elsewhere proved to be of benefit in uncovering systematic macroeconomic relationships that are often less well defined when only a single country's data are examined; for instance, in the examination of stagflation by Bruno and Sachs [1985]. While examining issues similar to the focus of the present paper, and while noting the work of Friedman, Feldstein and Fischer on the relationship between inflation and growth, Bruno and Sachs in fact conducted almost no empirical research into the direct relationship between inflation and growth - concentrating instead on relationships between wage and price inflation, institutional structures, unemployment, real wages and productivity. This concentration by Bruno and Sachs on changes in unemployment rather than on changes in growth is surprising given that they state: "For cross-country comparisons, the growth variable is probably a better simple indicator of the degree of resource utilisation than is the unemployment rate" [ibid., p. 219].

\footnotetext{
${ }^{1}$ The views expressed in the paper are those of the author and should not be attributed to my employer, the Reserve Bank of New Zealand. This paper was published as: Grimes, Arthur. 1991. "The Effects of Inflation on Growth: Some International Evidence", Weltwirtschaftliches Archiv, 127(4), 631-644.
} 
Their lack of concentration on growth is even more surprising given that they find that measures of changes in growth and changes in the unemployment rate across 17 countries are almost completely uncorrelated. The only evidence that they present on the relationship between inflation and growth is a simple cross-section equation for 17 countries which regresses the change in the inflation rate between 1973 and 1979 on the change in the average growth rate between $1965-73$ and 1973-79, finding a significant, positive relationship. However, as demonstrated later in this paper, a simple cross-country comparison, using only period average growth and inflation rate data, may hide important empirical regularities. This is particularly the case if significant supply-side factors have been omitted from the analysis.

Lucas [1973] and Taylor [1980] have examined the cross-country relationship between inflation and the level of output (compared with trend) but, with the exception of a brief mention by Lucas, do not examine the relationship between inflation and the growth of output. The exception is that Lucas notes that there is no significant association between average growth rates and average inflation rates across his sample of 18 countries $^{2}$ over the period 1952-67. However, such a comparison bears the same problems as for the Bruno and Sachs cross-country regression in that important empirical regularities may be hidden by the use solely of period average data in a cross-country comparison, and by the omission of supply-side factors.

Kormendi and Meguire [1985] examined the relationship between the change in the rate of inflation and economic growth within a cross-section regression containing 47 countries, using period average data over 1950-77. Their analysis differed from those already mentioned in that they included a number of other determinants of growth in their regression. They found that the change in inflation impacted negatively on growth over the period; this effect coming chiefly through a negative impact of changes in inflation on investment.

However, they did not examine the effect of the level of inflation on growth. Because of this omission, and because their work only uses period average data, it is unclear how to interpret their negative relationship between inflation changes and economic growth. For instance, it could be that the process of reducing inflation is beneficial to growth but that the level of inflation has no effect on growth. Conversely, their negative coefficient would be consistent with a situation where the resulting low inflation is beneficial. They recommended that a pooled time-series cross-section approach, as adopted here, could be useful in interpreting such matters.

Other work, which has attempted to examine the costs of inflation has also largely neglected to examine the possible link between the level of inflation and growth. Fischer [1981a; 1982], for instance, concentrated on the relationship between inflation and price variability, with only minor asides on the relationship between inflation and growth, and then only for the cases of the United States and Germany. Nevertheless, his work, and that of Bruno and Sachs, is valuable in that it highlights the need to account for the effects of major supply shocks (especially in the 1970s) when examining the effects of inflation. This requirement is taken into account in the current study.

In examining the relationship between inflation and any other variable, one must be aware of the distinction between anticipated and unanticipated inflation highlighted by Lucas [1976], Lucas demonstrated that a positive relationship may be found between inflation and output, whereas in fact the true positive relationship may be between unanticipated inflation and

\footnotetext{
${ }^{2}$ Although not reported explicitly by Lucas, the cross-country correlation coefficient between inflation and growth for all 18 countries in his study is -0.24 , while, omitting the two very high inflation countries - Argentina and Paraguay - the correlation coefficient is -0.31 ; neither of these coefficients is significantly different from zero at the 5 per cent level.
} 
activity, with no relationship holding between activity and anticipated inflation. While no attempt is made in the current study to distinguish between anticipated and unanticipated inflation, the risk of a spurious positive relationship being discovered between inflation and growth must be borne in mind; conversely, any finding of a negative relationship will be strengthened given this potential source of bias.

The following section of this paper discusses the methodology of the study and outlines the data to be used. Section 3 presents empirical tests of the relationship between inflation and growth. A brief summary completes the paper.

\section{Data and Methodology}

The study covers all 21 industrial countries, as classified by the IMF. Annual data is used and the period of analysis, except where otherwise stated, extends from 1961 to 1987. (In the case of Spain, 1987 GDP data was not available, so that in each case the Spanish equation ends in 1986). All data (apart from exceptions detailed in the Appendix) are obtained from the IMF's International Financial Statistics Yearbook [1988].

The inflation variable for year $t$ is the rate of wholesale price inflation between $t-1$ and $t$. While wholesale price inflation tends to weight tradeable goods more heavily than nontradeable goods, it is used in preference to consumer price inflation since wholesale prices are more likely to be measured on a comparable basis across countries, being less subject to idiosyncratic treatments of the effects of interest rates and housing prices in indices of consumer prices. In addition, wholesale prices are preferred to the GDP deflator in that the GDP deflator is also subject to measurement difficulties which may introduce a risk of errors in variables bias being introduced into the estimates. In particular, if nominal GDP is measured correctly, but there is an error in the real/price split of this aggregate, real GDP will erroneously appear to be high when the GDP deflator is low and vice versa.

Although the focus of attention is on the relationship between inflation and growth, it is considered necessary, given the warnings of Fischer and of Bruno and Sachs, also to include other possible determinants of economic growth in the analysis. In an attempt to account for various supply shocks, the percentage change in the terms of trade for each country is included as a possible determinant of growth, as is a time trend to take account of secular changes in the rate of technological progress. In the later estimates, year-specific dummies are included to account further for productivity and supply factors that have affected all countries simultaneously.

In addition to the inflation rate, the change in inflation is included as an explanatory variable to reflect potential short-run "Phillips curve" and/or Tobin-Mundell influences. Thus, the focus of attention for each country is an equation of the form (1), where, in some estimates, this equation is supplemented by year-specific dummies (constrained to be equal across countries).

$$
g p_{t}=a_{0}+a_{1} w i_{t}+a_{2} d w i_{t}+a_{3} d t t_{t}+a_{4} t i m e_{t}
$$

where: $g p_{t}=$ percentage growth rate in GDP between $\mathrm{t}-1$ and $\mathrm{t} ; \boldsymbol{w i}_{t}=$ percentage inflation rate in wholesale prices between $\mathrm{t}-1$ and $\mathrm{t} ; d w i_{t}=w i_{t}-w i_{t-1} ; d t t_{t}=$ percentage change in terms of trade between $\mathrm{t}-1$ and $\mathrm{t}$; time $_{t}=$ linear time trend.

Because the sample is limited to 27 observations on each country, it is desirable to use an estimation method and adopt testing procedures that are valid for small samples, rather than using procedures that are only asymptotically valid. For this reason, all equations are estimated using either ordinary least squares (OLS) or seemingly unrelated regressions (SUR). 
The danger of such an approach is that the estimates will be biased if any of the regressors are not weakly exogenous with respect to growth (although, a priori it is not apparent in which direction the coefficients on any of the variables would be biased). Unfortunately, the methods available to test for weak exogeneity are only asymptotically valid. While recognising this problem, the Hausman [1978] test for weak exogeneity has been employed for all 21 countries to examine whether there is any prima facie empirical evidence of endogeneity problems. The test involves regressing each of the explanatory variables on a set of exogenous instruments and including the residuals from each of these equations as additional explanatory variables in (1). One then tests whether the residual variables can validly be excluded from (1); because of the small number of degrees of freedom available, an F-test is used to test this restriction. In addition to the F-test, the individual t-statistic of each residual variable has been tested for significance. The instruments chosen for the first stage regressions include a constant, time trend plus the twice lagged value of each of $g p$, wi, $d w i$ and $d t t$ for each individual country. (One-period lagged values are inappropriate instruments as they may still be correlated with the growth rate between $\mathrm{t}-1$ and t.)

The results of this test procedure yield only one significant F-statistic at the 5 per cent (and 10 per cent) level (for Sweden) out of 21 tests. Two t-statistics are significant at the 5 per cent level and a total of five are significant at the 10 per cent level out of 63 coefficients. These results are approximately as may be expected to occur by chance and do not raise significant concerns regarding endogeneity. Hence OLS and SUR can be regarded as appropriate estimators.

In utilizing the same equation specification across all 21 countries, it is inevitable that some equations will perform less well than others in terms of explanatory power or in terms of the Durbin- Watson test for first-order autocorrelation (the only diagnostic statistic reported, given the small sample). The approach taken here is to retain consistent treatment of all countries, rather than to alter equations of particular countries, provided that the equations for most countries perform reasonably (particularly with regard to autocorrelation). This approach has the advantage that it effectively eliminates the use of "data-mining" [Learner, 1983], in determining the equation specifications.

\section{Estimation Results}

The simplest method to test the relationship between inflation and growth is to derive the correlation coefficient between the average growth rate and the average inflation rate in each country over the full sample period (1961-87), ignoring all other variables. This procedure yields a correlation coefficient of 0.065 , which is not significantly different from zero at any conventional level of significance. The finding of no significant correlation mirrors that of Lucas [1973], although it differs from that of Bruno and Sachs [1985] who found a positive, significant relationship between the two variables. However, a simple correlation coefficient may not be a well-constructed test of the inflation-growth relationship, since other factors which vary both across countries and across time are ignored.

Another simple approach is to estimate, for each country, a time series regression of growth on a constant, inflation, and (given the possible independent effect of disinflation) the change in inflation - i.e. (1) with $a_{3}$ and $a_{4}$ restricted to zero. The OLS results from such an equation are presented in Table 1 . In reporting these estimates, a "significant" coefficient has been interpreted as a coefficient that is significantly different from zero at the 20 per cent level on a 2-tailed test (or 10 percent on a 1-tailed test). A relatively high significance level is chosen for the discussion since, if a particular coefficient is significant at this level in a number of equations, then the true significance level across countries of the variable in question is considerably lower than 20 per cent.

The coefficient on inflation is negative in 19 of the 21 countries, and is significant in 12 of these cases. Neither of the two positive coefficients is significantly different from zero. But 
the opposite pattern emerges for the impact of the change in inflation on growth. Here 18 of the 21 coefficients are positive (12 significant); and the sum of the coefficients $\left(a_{1}+a_{2}\right)$ is positive in 12 cases. Thus, if attention is confined solely to the relation between inflation and growth, a reduction in inflation is estimated, on average, to reduce growth initially, but thereafter low inflation is estimated to contribute to a sustained increase in the growth rate. Thus, there is some empirical support for a short-run Phillips-curve relationship; but in the long run, inflation impacts negatively on economic growth.

The negative (long-term) influence of inflation on growth presented in Table 1 may, however, be spurious, because supply-side factors have been neglected. In order to capture some of these supply factors (such as changes in oil prices which affect the terms of trade), equation (1) is estimated without restrictions; the OLS results are presented in Table 2. Again 19 of the $a_{1}$ coefficients are negative (10 significant), while 19 of the $a_{2}$ coefficients are positive, the same pattern as previously. Changes in the terms of trade $\left(a_{3}\right)$ tend to have a positive influence on growth as expected, with 13 of the 21 coefficients positive (but only five of these are significant). The time trend appears to be of importance, with 19 of the $a_{4}$ coefficients being negative (10 significantly so), consistent with a slowdown in productivity growth over the period.

Although the results of Table 2 indicate the same negative relationship between inflation and growth as in Table 1, this finding may still be spurious if the supply factors have not adequately been captured by the terms of trade and time trend terms. Two additional modifications can be made in order to further capture the influence of supply factors.

Firstly, the equation residuals are likely to be correlated contemporaneously across countries owing to the impact that excluded variables may have on each of the countries in the same year. Therefore, it is preferable to estimate this system of equations using seemingly unrelated regressions so that the efficiency of the estimates can be improved. When (1) is re-estimated using SUR, but without any other changes, one finds that 16 of the $a_{1}$ coefficients remain negative (11 significant), 19 of the $a_{2}$ coefficients are positive, 12 of the $a_{3}$ coefficients are positive and 19 of the $a_{4}$ coefficients remain negative. Thus, while the negative impact of inflation on growth is no longer quite so pervasive, the estimated impact is still predominantly negative.

The second modification utilizes the SUR estimation technique by including year-specific dummies explicitly to capture the effects of worldwide influences on growth that occur independently of each of the country-specific factors. The coefficient on each year dummy is restricted to be equal in each country, so if the dummy for 1971 has an estimated coefficient of, say, -0.9 , the interpretation is that each country's growth rate in 1971 was lowered by 0.9 of a percentage point by factors acting independently of the influence of each of the countryspecific factors. In adopting this approach, all year dummies have been retained for the final estimates except where the absolute influence of such a dummy is less than half a percentage point; this procedure entailed the retention of all but six dummies (for 1961, 1962, 1963, 1965, 1970 and 1972).

Table 3 reports the results of estimating (1), supplemented by the year dummies, using SUR. Thirteen of the $a_{1}$ coefficients are now negative (11 significant); of the eight positive coefficients, four are significant. The $a_{2}$ coefficients are still predominantly positive (14 positive, of which 7 are significant) but there is now no clear direction of impact of the terms of trade or the time trend. The coefficients on the year dummies are all significantly different from zero and their sizes accord with intuition. In particular, the aftermath of the first oil shock is signalled by a coefficient on the 1975 dummy of -4.2 (per cent), while following the second oil shock there is a four-year growth slowdown indicated by the coefficients on the dummies from 1980 to 1983 of $-2.0,-3.4,-3.4$ and -3.0 , respectively. 
While the evidence of a negative impact of inflation on growth (and of a negative impact of disinflation on growth) is now less overwhelming than in the simple estimates reported in Tables 1 and 2, the direction of impact is still predominantly the same as before in each case.

The average impact and overall significance of inflation on growth across all countries can be obtained by re-estimating the results reported in Table 3 with the single modification that the $a_{1}$ coefficient be restricted to be equal across all countries. The estimate of this "average" $a_{1}$ is -0.11 . Thus, a sustained 9 percent annual inflation rate is estimated, on average, to lead to a permanent reduction in the annual growth rate of 1 percentage point. $^{3}$ This estimate is precisely determined, having a standard error of just 0.012 . The significance of this estimate supports the contention that, overall, there is a statistically significant negative effect of inflation on growth despite there being only 11 significant negative $a_{1}$ coefficients (at the 20 percent level) out of the sample of 21 countries.

\section{Summary}

The estimates presented in this paper suggest that even a low rate of inflation is likely to be detrimental to economic growth. These estimates are obtained using data for 21 countries over 27 years after allowance has been made for changes in inflation, changes in the terms of trade, a time trend and the impact of year-specific world-wide influences on growth. An annual inflation rate of approximately 9 per cent is estimated to decrease the annual growth rate by around 1 percentage point. This finding means that the costs of even a low inflation rate are estimated to be large given that it is the growth rate, not just the level of output, which is affected by inflation.

These results are a help in interpreting the findings of Kormendi and Meguire [1985]. It is likely that their finding of a negative impact of the average change in inflation on growth arises from the long-term detrimental effect of the level of inflation, rather than of the change in inflation on growth.

Comparison of these results with a simple indication of the relationship obtained from the correlation coefficient between the average inflation rate and the average growth rate in each country, demonstrates that the latter measure does not provide an accurate summary statistic. Studies that report such a statistic, without taking supply influences into account, should therefore be treated with caution.

\footnotetext{
${ }^{3}$ These estimates should not, however, be taken to imply that negative inflation will necessarily increase growth compared with a state of price stability. To demonstrate that this is not the case, a variant of equation (1) was estimated where the term $a_{1}$ wi $i_{t}$ was replaced by the term: $a_{1}\left|w i_{t}-i^{*}\right|$, where $i^{*}$ had to be estimated in addition to $a_{1}$. When this variant of (1) was estimated by non-linear SUR with year dummies and with $a_{1}$ and $i^{*}$ restricted to be equal across countries, the estimate of $a_{1}$ was again -0.11 with a standard error of 0.013 , while $i^{*}$ was estimated to be 0.98 (i.e. approximately 1 per cent) with a standard error of 0.47 .
} 


\section{Appendix}

Except as detailed below, all data are obtained from the IMF's International Financial Statistics Yearbook (IFSY) [1988].

Wholesale Price Inflation (wi and dwi)

Data for wi are obtained principally from IFSY (pp. 114-115). No data are available from this source for Iceland (1960-87), Australia (1960-69), Sweden (1960-68) and Luxembourg (1960-80); instead, inflation in the GDP deflator (from IFSY, pp. 168-169) is used for these countries over the stated periods. Data for France for 1986 and 1987 are taken from the IMF's International Financial Statistics (IFS) of June 1989, series Intermediate Industrial Goods (giving 1986 and 1987 inflation rates of -2.8 per cent and 0.2 per cent, respectively).

GDP Growth (gp)

Data for gp are obtained principally from IFSY (pp. 164-165). The 1987 growth figures for Canada, Finland, Ireland, Luxembourg and Switzerland are all obtained from IFS, June 1989 (being 4.0 percent, 3.8 percent, 4.1 percent, 3.7 percent and 2.3 percent, respectively). No 1987 data were obtainable for Spain from this source (so that all regressions for Spain finish in 1986). The data for New Zealand GDP growth in IFSY appear to have some major inaccuracies; for instance, growth rates of -20.8 and 15.8 percent are reported for 1975 and 1977 , respectively, neither of which bear any relation to official New Zealand data for these years. Because of these problems, the New Zealand gp series has been obtained from the Reserve Bank of New Zealand's database (using the series for real GDP measured on an expenditure basis) over the period 1963-87. The IFSY data are used for 1961 and 1962. (The splicing of the two series appears reasonable given that the growth data from the two sources are in close agreement over 1963-65).

Terms of Trade Changes (dtt)

Data for $d t t$ are obtained principally from IFSY (pp. 138-139). No $d t t$ data are available from this source for Belgium or Luxembourg; a proxy of industrial country $d t t$ (also available in IFSY, pp. 138-139) is used for these two countries. Data were obtained from IFS (June 1989) for France over 1986 and 1987 (11.8 and 0.7 per cent, respectively), Iceland for 1987 (0.1 percent), and Sweden for 1987 (-0.2 percent). 


\section{References}

Bruno, Michael, Jeffrey D. Sachs. 1985. Economics of Worldwide Stagflation. Harvard University Press, Cambridge MA.

Feldstein, Martin. 1982. "Inflation, Tax Rules and Investment: Some Econometric Evidence". Econometrica, Vol. 50, pp. 825-862.

Fischer, Stanley. 1977. "Long-Term Contracts, Rational Expectations, and the Optimal Money Supply Rule". Journal of Political Economy, Vol. 85, pp. 191-206.

Fischer, Stanley. 1981a. "Relative Shocks, Relative Price Variability, and Inflation". Brookings Papers on Economic Activity, No. 2, pp. 381-431.

Fischer, Stanley. 1981b. "Towards an Understanding of the Costs of Inflation: П". In: Karl Brunner, Alan H. Meltzer (Eds.), Carnegie- Rochester Conference Series on Public Policy, Vol.15, pp. 5-41.

Fischer, Stanley. 1982. "Relative Price Variability and Inflation in the United States and Germany". European Economic Review, Vol. 18, pp. 171-196.

Friedman, Milton. 1977. "Nobel Lecture: Inflation and Unemployment". Journal of Political Economy, Vol. 85, pp. 451-472.

Hausman, Jerry A. 1978. "Specification Tests in Econometrics". Econometrica, Vol. 46, pp. 1251-1271.

International Monetary Fund (IMF). Various years. International Financial Statistics Yearbook. Washington 1988.

Kormendi, Roger C, Philip G. Meguire. 1985. "Macroeconomic Determinants of Growth: Cross-Country Evidence". Journal of Monetary Economics, Vol. 16, pp. 141 - 164.

Leamer, Edward. 1983. "Let's Take the Con Out of Econometrics". The American Economic Review, Vol. 73, pp. 31-43.

Logue, Dennis E., Thomas D. Willett. 1976. "A Note on the Relation Between the Rate and Variability of Inflation". Economica, Vol.43, pp. 151-158.

Lucas, Robert E., Jr. 1973. "Some International Evidence on Output-Inflation Tradeoffs". The American Economic Review, Vol. 63, pp. 326-334.

Lucas, Robert E., Jr. 1976. "Econometric Policy Evaluation: A Critique". In: Karl Brunner, Alan H. Meltzer (Eds.), Carnegie-Rochester Conference Series on Public Policy, Vol. 1, pp. $19-46$.

Taylor, John B. 1980. "Output and Price Stability: An International Comparison". Journal of Economic Dynamics and Control, Vol. 2, pp. 109-132. 
Table 1 - OLS Estimates (excluding supply factors)

\begin{tabular}{|c|c|c|c|c|c|}
\hline Country & $\alpha_{0}$ & $\alpha_{1}$ & $\alpha_{2}$ & $\mathrm{R}^{2}$ & D.W. \\
\hline United States & $4.31^{*}$ & $-0.26^{*}$ & $0.34^{*}$ & 0.42 & 1.75 \\
\hline Canada & $5.11^{*}$ & $-0.16^{+}$ & $0.34^{*}$ & 0.25 & 2.00 \\
\hline Australia & $6.26^{*}$ & $-0.33^{*}$ & $0.36^{*}$ & 0.38 & 2.39 \\
\hline Japan & $7.85^{*}$ & $-0.25^{+}$ & $0.17^{\circ}$ & 0.15 & 0.65 \\
\hline New Zealand & $3.95^{*}$ & -0.16 & -0.04 & 0.08 & 2.12 \\
\hline Austria & $3.74^{*}$ & -0.11 & $0.19^{+}$ & 0.13 & 1.26 \\
\hline Belgium & $3.82^{*}$ & -0.10 & $0.27^{*}$ & 0.25 & 1.38 \\
\hline Denmark & $4.58^{*}$ & $-0.23^{*}$ & $0.14^{\circ}$ & 0.22 & 1.89 \\
\hline Finland & $4.40^{*}$ & -0.07 & 0.13 & 0.06 & 1.62 \\
\hline France & $4.86^{*}$ & $-0.15^{+}$ & $0.16^{*}$ & 0.23 & 0.95 \\
\hline West Germany & $3.12^{*}$ & 0.00 & 0.20 & 0.04 & 2.14 \\
\hline Iceland & $8.11^{*}$ & $-0.13^{*}$ & -0.02 & 0.29 & 1.22 \\
\hline Ireland & $3.55^{*}$ & 0.03 & 0.13 & 0.08 & 1.44 \\
\hline Italy & $5.39^{*}$ & $-0.18^{*}$ & $0.26^{*}$ & 0.66 & 1.27 \\
\hline Netherlands & $4.79^{*}$ & $-0.34^{+}$ & 0.23 & 0.13 & 1.09 \\
\hline Norway & $5.09^{*}$ & -0.13 & 0.12 & 0.07 & 1.52 \\
\hline Sweden & $4.20^{*}$ & $-0.17^{+}$ & $0.15^{+}$ & 0.17 & 1.25 \\
\hline Switzerland & $3.10^{*}$ & -0.16 & $0.42^{*}$ & 0.34 & 0.92 \\
\hline United Kingdom & $3.67^{*}$ & $-0.16^{*}$ & -0.05 & 0.28 & 1.88 \\
\hline Luxembourg & $3.89^{*}$ & -0.01 & 0.11 & 0.08 & 1.65 \\
\hline Spain & $8.66^{*}$ & $-0.44^{*}$ & $0.43^{*}$ & 0.63 & 1.47 \\
\hline \multicolumn{6}{|c|}{$\begin{array}{l}\text { Note: Coefficients are as in equation (1), with } \alpha_{3} \text { and } \alpha_{4} \text { restricted to zero. - Al } \\
\text { estimates are for } 1961-87 \text { (except Spain, } 1961-86) .- \text { The symbols }{ }^{*}\left[{ }^{+}\right]\left({ }^{\circ}\right) \text { indicat } \\
\text { significantly different from zero at the } 5 \text { per cent }[10 \text { per cent] }(20 \text { per cent) leve } \\
\text { respectively on a } 2 \text {-tailed test. }\end{array}$} \\
\hline
\end{tabular}


Table 2 -OLS Estimates (including supply factors)

\begin{tabular}{|c|c|c|c|c|c|c|}
\hline Country & $\alpha_{1}$ & $\alpha_{2}$ & $\alpha_{3}$ & $\alpha_{4}$ & $\mathrm{R}^{2}$ & D.W. \\
\hline United States & $-0.16^{\circ}$ & $0.42^{*}$ & $0.21^{\circ}$ & -0.02 & 0.48 & 1.52 \\
\hline Canada & $-0.14^{\circ}$ & 0.20 & 0.18 & -0.05 & 0.31 & 2.16 \\
\hline Australia & $-0.36^{*}$ & $0.38^{*}$ & -0.01 & $0.02^{*}$ & 0.39 & 2.40 \\
\hline Japan & $-0.32^{*}$ & $0.16^{*}$ & -0.04 & -0.40 & 0.73 & 1.85 \\
\hline New Zealand & -0.04 & -0.14 & $0.11^{\circ}$ & -0.13 & 0.17 & 1.98 \\
\hline Austria & -0.11 & $0.16^{\circ}$ & 0.01 & $-0.12^{*}$ & 0.36 & 1.71 \\
\hline Belgium & -0.06 & $0.22 *$ & 0.00 & $-0.17^{*}$ & 0.54 & 2.18 \\
\hline Denmark & -0.10 & $0.13^{\circ}$ & 0.19 & $-0.13^{*}$ & 0.37 & 2.22 \\
\hline Finland & -0.04 & 0.13 & 0.12 & -0.07 & 0.13 & 1.64 \\
\hline France & -0.00 & $0.10^{*}$ & 0.10 & $-0.21^{*}$ & 0.63 & 1.63 \\
\hline West Germany & 0.22 & $0.40^{\circ}$ & $0.29^{\circ}$ & -0.00 & 0.12 & 2.13 \\
\hline Iceland & $-0.16^{*}$ & 0.01 & $0.22^{*}$ & 0.19 & 0.43 & 1.33 \\
\hline Ireland & 0.07 & 0.07 & -0.02 & $-0.10^{\circ}$ & 0.19 & 1.59 \\
\hline Italy & $-0.13^{*}$ & $0.25^{*}$ & 0.03 & $-0.10^{+}$ & 0.71 & 1.50 \\
\hline Netherlands & $-0.28^{+}$ & 0.09 & -0.19 & $-0.18^{*}$ & 0.39 & 1.40 \\
\hline Norway & -0.03 & 0.07 & -0.02 & -0.08 & 0.13 & 1.62 \\
\hline Sweden & -0.05 & $0.23^{*}$ & $0.33^{*}$ & $-0.14^{*}$ & 0.51 & 1.53 \\
\hline Switzerland & $-0.28^{+}$ & $0.35^{*}$ & $-0.21^{\circ}$ & $-0.15^{*}$ & 0.56 & 1.03 \\
\hline United Kingdom & $-0.13^{*}$ & $-0.22^{*}$ & $-0.27^{*}$ & -0.01 & 0.49 & 1.80 \\
\hline Luxembourg & -0.01 & 0.11 & -0.05 & -0.03 & 0.10 & 1.62 \\
\hline Spain & $-0.22^{*}$ & $0.22^{+}$ & 0.00 & $-0.23^{*}$ & 0.77 & 1.72 \\
\hline \multicolumn{7}{|c|}{$\begin{array}{l}\text { Note: Coefficients are as in equation }(1) ; \alpha_{0} \text { not reported. }- \text { All estimates are for } \\
1961-87 \text { (except Spain, } 1961-86) \text {. The symbols }{ }^{*}\left[{ }^{+}\right]\left({ }^{\circ}\right) \text { indicate significantly } \\
\text { different from zero at the } 5 \text { per cent }[10 \text { per cent }](20 \text { per cent) level respectively on } \\
\text { a 2-tailed test. }\end{array}$} \\
\hline
\end{tabular}


Table 3 - SUR Estimates (including year dummies)

\begin{tabular}{|l|rrrrrr|}
\hline Country & \multicolumn{1}{|c}{$\alpha_{1}$} & $\alpha_{2}$ & $\alpha_{3}$ & $\alpha_{4}$ & $\mathrm{R}^{2}$ & D.W. \\
\hline United States & $-0.17^{*}$ & $0.25^{*}$ & $0.18^{*}$ & $0.11^{*}$ & 0.41 & 1.43 \\
Canada & $-0.15^{*}$ & $0.08^{\circ}$ & $0.08^{*}$ & $-0.07^{\circ}$ & 0.34 & 2.11 \\
Australia & $-0.25^{*}$ & 0.10 & -0.02 & $0.12^{*}$ & 0.30 & 2.43 \\
Japan & $-0.24^{*}$ & 0.04 & $-0.07^{*}$ & $-0.26^{*}$ & 0.74 & 1.81 \\
New Zealand & 0.03 & $-0.18^{*}$ & 0.04 & -0.03 & 0.33 & 1.95 \\
Austria & 0.04 & 0.02 & -0.04 & 0.01 & 0.59 & 2.32 \\
Belgium & -0.05 & $0.08^{*}$ & $-0.12^{+}$ & -0.04 & 0.71 & 2.60 \\
Denmark & $-0.08^{\circ}$ & -0.04 & 0.06 & -0.01 & 0.59 & 2.23 \\
Finland & $0.07^{+}$ & -0.03 & $0.10^{*}$ & 0.04 & 0.39 & 1.49 \\
France & 0.01 & 0.01 & -0.00 & $-0.08^{*}$ & 0.69 & 1.71 \\
West Germany & $0.33^{*}$ & -0.07 & $0.27^{*}$ & $0.10^{\circ}$ & 0.26 & 2.11 \\
Iceland & $-0.19^{*}$ & 0.04 & $0.17^{*}$ & $0.35^{*}$ & 0.45 & 1.34 \\
Ireland & $0.11^{*}$ & 0.02 & $-0.09^{+}$ & 0.02 & 0.17 & 1.81 \\
Italy & $-0.07^{*}$ & $0.18^{*}$ & -0.00 & 0.02 & 0.55 & 1.25 \\
Netherlands & $-0.18^{*}$ & $-0.06^{\circ}$ & $-0.25^{*}$ & $-0.05^{\circ}$ & 0.68 & 0.99 \\
Norway & $0.18^{+}$ & $-0.14^{+}$ & -0.03 & -0.00 & 0.04 & 1.49 \\
Sweden & $0.08^{\circ}$ & 0.05 & $0.26^{*}$ & -0.04 & 0.56 & 1.52 \\
Switzerland & $-0.27^{*}$ & $0.29^{*}$ & $-0.10^{\circ}$ & -0.02 & 0.58 & 1.35 \\
United Kingdom & $-0.08^{*}$ & $-0.20^{*}$ & $-0.16^{*}$ & $0.11^{*}$ & 0.48 & 2.32 \\
Luxembourg & -0.02 & $0.07^{*}$ & 0.07 & $0.10^{*}$ & 0.53 & 1.68 \\
Spain & $-0.13^{*}$ & $0.09^{\circ}$ & 0.30 & $-0.16^{*}$ & 0.81 & 1.50 \\
Note: Coefficients are as in equation $(1) ; \alpha_{0}$ and coefficients on year-specific dum- \\
mies are not reported. - All estimates are for 1961-87 (except Spain, 1961-86). \\
- The symbols ${ }^{*}\left[^{+}\left(^{\circ}\right.\right.$ ) indicate significantly different from zero at the 5 per cent \\
[10 per cent] (20 per cent) level respectively on a 2-tailed test. & & \\
\hline
\end{tabular}

